\title{
Effects of Subjective Successful Aging on Emotional and Coping Responses to the COVID-19 Pandemic
}

\section{Dannii Yeung ( Dannii.yeung@cityu.edu.hk)}

City University of Hong Kong

\section{Edwin Chung}

City University of Hong Kong

Alfred Lam

City University of Hong Kong

Alvin Ho

City University of Hong Kong

\section{Research Article}

Keywords: coronavirus disease, subjective perceptions of successful aging, perceived time limitation, emotional and coping responses

Posted Date: November 6th, 2020

DOI: https://doi.org/10.21203/rs.3.rs-102941/v1

License: (c) (i) This work is licensed under a Creative Commons Attribution 4.0 International License. Read Full License 


\section{Abstract}

Background: Middle-aged and older adults are more vulnerable to hospitalization and mortality if they are infected with the COVID-19 virus. The present study investigates the longitudinal effects of subjective successful aging on middle-aged and older adults' emotional and coping responses to the COVID-19 pandemic, and explores an underlying mechanism through perceived time limitation during the pandemic.

Methods: A sample of 311 Hong Kong Chinese middle-aged and older adults $\left(M_{a g e}=64.58, S D=10.14\right.$, Range $=45-90$ years) were recruited from an Adult Development and Aging Project and participated in a questionnaire study via an online platform or phone interview. Their levels of subjective successful aging, perceived time limitation, and emotional and coping responses to the pandemic were measured.

Results: The respondents who perceived themselves as more successful in aging process reported more positive and fewer negative emotions compared with their counterparts with lower levels of subjective successful aging. The mediation analysis showed that perceived time limitation could partially account for the effects of subjective successful aging on emotional and coping responses.

Conclusions: Findings of this study unveil the beneficial effects of subjective views of successful aging on emotional and coping responses to the pandemic through alleviating their perception of time limitation.

\section{Background}

A novel infectious disease named the coronavirus disease 2019 (COVID-19) was first identified in December 2019 in Wuhan, China, and has spread globally from February 2020 onwards. The World Health Organization (WHO) formally announced COVID19 as a pandemic on 11 March 2020. In response to this pandemic, multiple preventive measures have been implemented in Hong Kong (HK) since late January. For example, "work from home" arrangements were implemented for civil servants between 29 January and 3 May 2020. Similar measures have also been adopted in private and public organizations. Moreover, social distancing measures have been implemented since 28 March 2020, including the temporary closure of public entertainment places, such as theatres and fitness centers [1]. High perceived uncertainty and susceptibility among local residents were likewise observed because of the lack of information on the means of infection and effective treatment in the early stages of the pandemic [2]. The acute surgical mask shortage at the onset of the outbreak also precipitated panic and anger, and social distancing measures considerably interrupted work arrangements and social relationships. As of 11 March 2020, there were 129 confirmed cases in HK, with a mean age of 55.9 ( $S D=16.9$; Range=16-96) [3], thereby suggesting that middle-aged and older adults are the most vulnerable age groups to this disease. Therefore, the present study aims to identify the factors influencing their emotional and coping responses to the COVID-19 pandemic.

\section{Successful aging}

The literature on successful aging has provided a fundamental theoretical basis to understand middle-aged and older adults' responses to the unexpected and life-threatening COVID-19. Despite the lack of consensus on a formal definition for successful aging, researchers generally agree that successful aging appears as a multicomponent concept that often includes relatively good physical and mental functioning $[4,5,6]$. Rowe and Kahn's three major objective criteria [7] have been widely adopted among the many conceptualizations for successful aging: the absence of disease and disease-related disability, maintenance of high cognitive and physical functioning, and active engagement with life. Their definition of successful aging has facilitated the differentiation of successful agers (i.e., older adults whose health and social adjustments are above average) from normal agers, and inspired numerous studies from diverse disciplines to examine the prevalence and correlates of successful aging globally [8, 9]. Although this conceptualization of successful aging is popular, it has been criticized for its biomedical focus and lack of lay perception in defining what constitutes successful aging $[10,11]$.

Given these criticisms on Rowe and Kahn's conceptualization for successful aging, more attention has been redirected to the field of subjective successful aging $[12,13,14]$. Aging is a dynamic lifelong process, such that an individual may perceive themselves having aged successfully at one point in their lives but not at others [15], or being successful in one domain of successful aging 
but not the others [16]. Subjective successful aging is considered as a self-appraisal of their own aging process over multiple dimensions of later life $[13,17]$. The self-evaluation procedure of successful aging involves simultaneous weighting over multiple aspects of later life as well as comparing own aging trajectory with their peers [18], therefore, it is more comprehensive and precise in reflecting older individuals' perception of their own aging process. While further investigations for the conceptualizations of successful aging among laypeople are needed, in the current state, studies often utilize a single item to measure subjective successful aging $[17,19,20]$. Evidence has suggested that self-rated successful aging had stronger associations with older adults' well-being than Rowe and Kahn's objective criteria of successful aging [19, 20, 21]. Studies also consistently reveal that higher levels of self-rated successful aging are associated with better physical functioning, higher levels of resilience, and fewer depressive symptoms $[17,19]$. In a longitudinal study conducted over the course of 23 years, positive selfperception of aging was found to contribute to the survival rate of Americans [22].

Previous studies have demonstrated that a positive view of aging is one of the major protective factors against the negative effects of aging on physical and psychosocial well-being. For example, Dutt et al. showed that the awareness of age-related gains and losses are linked to the use of adaptive regulatory behaviors such as assimilation and accommodation [23]. Using a hypothetical risk-taking task, Brassen et al. demonstrated that successful agers exhibited a greater tendency to regulate emotions than their non-successful counterparts [24]. Moreover, relative to normal agers, successful agers have been found to actively utilize adaptive strategies (such as loss-based selection) to manage their negative emotional experiences [25] and proactively deal with future stressors to prevent the occurrence of negative events or potential losses [26, 27]. This reveals a potential linkage between subjective successful aging and the use of problem-focused coping. Inferring from these findings, it is therefore anticipated that individuals with a higher self-rating of successful aging may prefer problem-focused coping over emotionfocused coping, and may exhibit improved affective well-being in response to the pandemic.

Evidently, people of older age, particularly those with chronic diseases, are significantly vulnerable to COVID-19 and its impacts. The implementation of social distancing measures further restricts social activities of older people, creating a potential threat to their social and psychological well-being. The COVID-19 pandemic thus provides a platform to examine the long-term impacts of subjective successful aging in the face of a naturalistic negative event, and to investigate whether perceived time limitation caused by the pandemic can be one of the underlying mechanisms. Accordingly, the present study investigates whether middleaged and older adults with higher scores of self-rated successful aging would exhibit better adjustment during the pandemic.

\section{Perceived time limitation}

Previous research on the responses facing unexpected and uncontrollable crises such as to the September 11 attacks in the United States and the SARS outbreak in Hong Kong has provided a salient reminder that life is finite [28]. The same situation should be applicable to the current COVID-19 pandemic. Despite the lack of studies directly linking subjective successful aging and perceived time limitation together, individuals' views of their own aging process provide them with a frame for future expectations and their perceived controllability in face of certain events, subsequently influencing their regulatory behaviors [29]. Individuals with higher levels of subjective successful aging are expected to perceive their futures as considerably optimistic and open-ended, and vice versa for those with lower levels of subjective successful aging.

Building on the theoretical proposition of socioemotional selectivity theory [30], previous research has demonstrated that future time perception accounts for the observed age differences in goal orientations, social preferences, emotional and coping responses. Future time perception motivates people to focus on the present moment and emotionally meaningful experiences. Thus, people prefer interacting with emotionally close social partners over acquaintances [31, 32]. Moreover, individuals with an open-ended future time perception exhibit a greater use of problem-focused coping [27, 33], and report greater positive emotions and fewer negative emotions [34]. By contrast, individuals with limited future time perception utilize more emotion-focused coping to manage emotional experiences [28], report lower levels of subjective well-being [34], and was linked to the substantial use of maladaptive conflict management strategies [35]. Therefore, the present study further investigates whether individuals with higher levels of subjective successful aging would be less likely to have limited time perception, thereby resulting in better emotional well-being and greater utilization of adaptive coping strategies during the pandemic.

\section{Emotional and coping responses to the pandemic}


Negative emotions are often accompanied with uncontrollable and unexpected life events. In the examination of emotional and coping responses to the SARS outbreak, Hong Kong people, regardless of their age, were found to exhibit intense negative emotions, such as anxiety, fear and worry, and utilized more problem-focused strategies than emotion-focused strategies to cope with the outbreak [36]. To extend these findings, additional effort is required to examine which factors would predict middle-aged and older adults' emotional and coping responses to the COVID-19 pandemic. The present study aims to fill this knowledge gap through the lens of subjective successful aging and time limitation.

Different from the SARS outbreak, the Hong Kong government has implemented social distancing practices since 28 March 2020 to prohibit social gatherings of over four people to prevent the spread of the COVID-19 virus [37]. Such a requirement significantly reduces older people's interactions with their family members and close friends. Given that they are the major sources of emotional satisfaction among middle-aged and older adults [38], these preventive measures may induce more intense negative feelings toward life and future, thereby resulting in elevated frustration and loneliness. It is therefore questioned whether individuals with higher levels of subjective successful aging would adapt to these changes better than those with lower levels of subjective successful aging.

The present study formulated four hypotheses by integrating the models and research on successful aging and lifespan development:

Hypothesis 1: Individuals with higher levels of subjective successful aging will be less likely to report time limitation during the pandemic than those with lower levels of subjective successful aging.

Hypothesis 2: Individuals with higher levels of subjective successful aging will experience more positive and fewer negative emotions than those with lower levels of subjective successful aging.

Hypothesis 3: Individuals with higher levels of subjective successful aging will use more problem-focused coping strategies and fewer emotion-focused coping strategies than those with lower levels of subjective successful aging.

Hypothesis 4: Perceived time limitation will mediate the longitudinal effects of subjective successful aging on emotional and coping responses. In particular, individuals with higher levels of subjective successful aging are expected to hold a more openended time perception during the pandemic than those with lower levels of subjective successful aging, which is subsequently associated with more positive and fewer negative emotions, and more problem-focused and fewer emotion-focused coping.

\section{The present study}

Given that the means of infection and medicine were unknown and unavailable in the early stages of the COVID-19 pandemic, many people, especially middle-aged and older adults who are more vulnerable to greater rates of hospitalization and mortality if infected, were anxious and worried about the threat of infection. To adequately understand individual differences in reactions to this global health calamity, the present study investigates the longitudinal effects of subjective successful aging on the emotional and coping responses to the COVID-19 pandemic. The mediating role of perceived time limitation caused by the pandemic will also be examined. The findings of this study will contribute to the literature on successful aging by unveiling an underlying mechanism between subjective successful aging and emotional and coping responses to the pandemic.

\section{Methods}

\section{Participants and procedures}

A questionnaire was developed to measure middle-aged and older Hong Kong Chinese adult's responses to COVID-19 pandemic. The participants were recruited from the longitudinal database on Adult Development and Aging. A total of 311 participants were successfully contacted and consented to take part in this COVID-19 questionnaire (response rate $=62.1 \%$ ). Their mean age was 64.58 ( $S D=10.14$; Range $=45-90$ years), $73 \%$ were female, and $25.4 \%$ were employed during the pandemic. The majority of the respondents $(61.1 \%)$ had completed secondary school or an associate degree. The mean age and subjective successful aging between the participants who participated in the COVID-19 questionnaire and those who did not were not statistically different. 
Ethical approval for human research was obtained from the affiliated university for both the COVID-19 study and the longitudinal study on Adult Development and Aging. Except for subjective successful aging, the variables related to the COVID-19 pandemic were collected between March 29 and April 24, 2020. The commencement date of the COVID-19 study was four days after the HKSAR government's implementation of border closure to non-residents and compulsory quarantine order for returning residents [39]. The participants who were contacted via instant message or email completed an online survey via the Qualtrics platform, while those who were contacted by phone completed a telephone survey which was conducted by trained interviewers. Prior to participation, written consent was obtained from the participants who completed the study online whereas verbal consent was sought from the participants who were interviewed over the phone. Verbal consent was used because the COVID-19 study was conducted during the peak of the pandemic in Hong Kong, and the government encouraged people to stay at or work from home. The use of the verbal consent had been approved by the Human Subjects Ethics Sub-committee of the affiliated university. It took approximately 10 minutes to complete the questionnaire. Participation in this study was voluntary and no financial incentive was provided.

\section{Measures}

Emotional and coping responses and perceived time limitation during the pandemic were measured in the COVID-19 survey [Supplementary file], whereas subjective successful aging was measured in the baseline survey of the Adult Development and Aging Project in 2019 [55].

Emotional responses to the pandemic. With reference to previous studies assessing emotional responses to negative events [36, 40], the participants were asked to rate the extent of their emotional reactions to the COVID-19 pandemic in Hong Kong, including four negative emotions (afraid, anxious, nervous, and upset) and four positive emotions (happy, calm, active, and attentive). In addition, two items were included to measure their feelings in response to reduced social contact owing to social distancing measures: "I felt frustrated because of the reduced social contact" and "I felt lonely because of the reduced social contact." The 10 emotion items were rated using a five-point scale, ranging from $1=$ not at all to $5=$ very much. The Cronbach's alphas (a) of the negative and positive emotions were .90 and .75, respectively, whereas the alpha of the negative reactions to reduced social contact was .91 .

Coping strategies. The measurement assessing the participants' means to cope with the COVID-19 pandemic was adapted from the previous measures of problem-focused and emotion-focused coping strategies used in the SARS outbreak [36], which were developed based on the Brief COPE scale [41]. In particular, four items measured problem-focused coping (active coping, and instrumental support from family members, friends, and mass media) and six items measured emotion-focused coping (selfdistraction, behavioral disengagement, positive reframing, use of emotional support, venting toward family members and on social media). The participants indicated how often they used each strategy to cope with the COVID-19 pandemic using a fivepoint scale, ranging from $1=$ none to $5=$ always. Higher scores represent a greater use of the strategies. The Cronbach's alphas of the problem- and emotion-focused coping strategies were .65 and .66 , respectively.

Perceived time limitation. Given the time constraint of the telephone survey, only one item was selected and adapted from the Future Time Perspective Scale $[42,43]$ to measure the participants' perceived time limitation in response to the pandemic. Specifically, "The COVID-19 pandemic makes me feel that time is running out" was rated using a five-point Likert scale, ranging from $1=$ strongly disagree to $5=$ strongly agree. Higher scores represent a stronger sense of limited time remaining in life.

Subjective successful aging. The participants' self-appraisal towards their own aging process were measured by a single statement commonly used in the literature $[17,19,20]$. Specifically, participants were asked to indicate their agreement to the statement "I am aging successfully" on a 7-point Likert scale (1=strongly disagree and 7=strongly agree), with higher scores indicating higher levels of subjective successful aging.

Covariates. The participants' perceived severity of the pandemic and level of reduced social contact due to the social distancing measures were also assessed in the COVID-19 questionnaire. Both questions were rated on a 5-point rating scale (1=strongly disagree and 5=strongly agree), with higher scores representing a greater level of the respective construct. The participants' demographic variables including age, gender $(1=$ male and $2=$ female), and education level ( 1 = primary school education or below, 2 = secondary school education, and 3 = Bachelor's degree or above) were extracted from the longitudinal database on 
Adult Development and Aging, whereas their current work status $(0=$ not employed and $1=$ employed $)$ was measured in the COVID-19 questionnaire.

\section{Results}

\section{Descriptive statistics}

Table 1 presents the means and correlations of the demographic and major variables. Subjective successful aging was significantly correlated with negative and positive emotions ( $r=-.31$ and $r=.40$, respectively), negative reactions to reduced social contact $(r=-.25)$, problem-focused coping $(r=.24)$, emotion-focused coping $(r=.12)$, and perceived time limitation $(r=-.18)$, $p s<$ .05. Moreover, perceived time limitation was significantly correlated with fewer positive emotions and more emotion-focused coping ( $r=-.20$ and $r=.23$, respectively, $p s<.05)$. In addition, over $62 \%$ and $77 \%$ of the participants agreed or strongly agreed that the COVID-19 pandemic was severe and reduced their levels of social contact, respectively, indicating substantial impacts of the pandemic on the participants.

<insert Table 1 here>

\section{Direct and indirect effects of subjective successful aging on emotional and coping responses}

To test the four hypotheses, a mediation analysis was performed using the $\mathrm{R}$ package lavaan [44] with subjective successful aging as the independent variable, perceived time limitation as the mediator, and emotional and coping responses as the five dependent variables. Age, gender, education level, work status, perceived severity of the pandemic, and level of reduced social contact were controlled as covariates because they were significantly correlated with subjective successful aging, perceived time limitation, or emotional and coping responses. Figure 1 presents the results of the mediation model and Table 2 reports the total, direct and indirect effects.

<insert Table 2 here>

The results of the mediation model showed that the participants with higher levels of subjective successful aging were less likely to report time limitation during the pandemic than those with lower levels of subjective successful aging $(B=-.12, S E=.04, p$ $=.001)$. Therefore, $\mathrm{H} 1$ is supported. In terms of the direct effects proposed in $\mathrm{H} 2$ and $\mathrm{H} 3$, subjective successful aging were found to be predictive of all five dependent variables, including negative emotions $(B=-.15, S E=.03, p<.001)$, positive emotions ( $B=$ $.19, S E=.03, p<.001)$, negative reactions to reduced social contact $(B=-.14, S E=.04, p<.001)$, problem-focused coping $(B=.12$, $S E=.03, p<.001)$, and emotion-focused coping $(B=.07, S E=.02, p=.003)$, even after controlling for the six covariates. However, the effect of subjective successful aging on emotion-focused coping was positive, which was contradictory to the hypothesized pattern. Consequently, $\mathrm{H} 2$ is supported, while $\mathrm{H} 3$ is partially supported.

The significant indirect effects of subjective successful aging through perceived time limitation were found on negative emotions $(B=-.03, S E=.01, p=.007)$, positive emotions $(B=.02, S E=.01, p=.025)$, negative reactions to reduced social contact $(B=-.02, S E=.01, p=.027)$, and emotion-focused coping $(B=-.02, S E=.01, p=.013)$. However, such effects were not observed on problem-focused coping. Consequently, $\mathrm{H} 4$ is partially supported.

\section{Discussion}

The outbreak of COVID-19 has produced severe threats to public health and has caused substantial economic and social stresses globally. The pandemic has also created continuous interruptions and changes to daily life and social relationships. Middle-aged and older adults are particularly at risk because of higher rates of infection and severe symptoms [45]. This study attempted to advance the current literature on successful aging by investigating the responses of these two vulnerable age groups to this novel disease. The results of this study demonstrated that relative to those with lower levels of subjective successful aging, people with higher levels of subjective successful aging exhibited better affective well-being and lower utilization of emotion-focused coping during the COVID-19 pandemic through regulating their perceptions of future time. 


\section{Effects of subjective successful aging on responses to the pandemic}

Previous studies have demonstrated that internalized views of aging increase people's utilization of preventive health services [46] and adaptive behaviors [23]. The present study advances the current literature on successful aging and reveals that holding positive self-appraisal towards the aging process enables individuals to actively utilize adaptive strategies (such as active planning and use of instrumental support) to deal with the changes and interruptions caused by the pandemic and the implementation of social distancing practices in society. Compared to individuals with lower levels of subjective successful aging, those with higher levels of subjective successful aging are more likely to experience fewer negative and more positive emotions in response to the pandemic and the imposed social distancing measures in Hong Kong, and display a greater use of various coping strategies to deal with the virus. By contrast, individuals with lower levels of subjective successful aging showed intense negative emotions and did not actively cope with the COVID-19 outbreak. Thus, the findings of this study further demonstrate the beneficial effects of subjective successful aging on well-being even in the face of the COVID-19 pandemic.

\section{Mediating effects of perception of time limitation}

The socioemotional selectivity theory [30] stresses that when people perceive that their future is running out of time, their goal orientations will shift from knowledge-related goals to emotional goals. Previous studies have demonstrated that perceptions of future time, either self-rated or experimentally manipulated, account for the age-related differences in social preferences [32], emotional experiences [34], and use of coping strategies [33,47]. Similar to other past life-threatening crises, such as the SARS outbreak in 2003 and the September 11 attacks, the COVID-19 pandemic is accompanied with a wide range of uncertainties for the future, thereby resulting in a heightened sense of time limitation. The present findings further showed that greater perceived time limitation was prevalent among the participants with lower levels of subjective successful aging than those with higher levels of subjective successful aging. As predicted, such a heightened sense of time limitation was associated with more negative and fewer positive emotions, and greater utilization of emotion-focused coping strategies. As a result, better affective well-being and fewer employment of emotion-focused coping were observed among individuals who held optimistic views of successful aging than those with pessimistic views, and the differences in emotional and coping responses between individuals with higher and lower levels of subjective successful aging are partially explained by their levels of perceived time limitation. These findings unveil a mechanism underlying the relationships between internalized views of successful aging and responses to the pandemic through perceived time limitation, and lend further support to the socioemotional selectivity theory [30]. That is, the perception of future time plays an important role in influencing emotional and behavioral responses, even in the face of life-threatening situations.

From the experiences in the SARS outbreak in 2003 [36], Hong Kong people, compared with people in other countries, generally show a higher tendency to perform preventive measures to reduce the likelihood of COVID-19 infection, such as wearing surgical masks, washing hands regularly, or seeking instrumental support from family members and friends. Contrary to our prediction, the present study did not find any significant main or mediating effects of perceived time limitation on problem-focused coping. Instead, subjective successful aging was found to be positively associated with the use of problem-focused coping during the pandemic. In line with previous findings [26, 27], successful agers hold positive perceptions of their capabilities to manage life challenges and adversities, thus show a greater tendency to proactively deal with the stressors [26] and utilize active planning and adaptive strategies [48].

Practical implications can be drawn from the beneficial effects of cultivating higher levels of subjective successful aging shown in the present study. As subjective successful aging involves self-evaluations of one's own aging process in face of inevitable functional decline, individuals with higher levels of subjective successful aging are those with higher perceived capacities in managing age-related losses. Therefore, social activities and intervention programs targeting older adults should focus on cultivating their perceived capabilities to deal with life challenges. For example, volunteering activities and group-based interventions can cultivate one's sense of control [49], resilience [50], or empowerment [51]. These values can foster a greater sense of subjective successful aging and promote adaptive coping during adverse events such as a pandemic.

\section{Limitations and future directions}


The current study integrates the data collected before the COVID-19 pandemic (i.e., subjective successful aging) and during its peak (i.e., perceived time limitation and emotional and coping responses), and reveals a mechanism underlying the relationships between subjective successful aging and responses to the coronavirus and social distancing measures in Hong Kong. However, several limitations should be considered when interpreting the previously discussed findings. First, despite the fact that the singleitem measure for subjective successful aging was commonly used in previous studies $[17,19]$, and was found positively correlated with self-rated health $(r=.35, p<.001)$ and perceived mastery $(r=.57, p<.001)$ in the entire sample of the baseline survey of the Adult Develop and Aging project $(\mathrm{N}=501)$, its construct validity may not be well demonstrated in the present study. Future studies may consider assessing subjective successful aging with a more comprehensive assessment. Similarly, with the consideration of keeping each telephone interview short, perceived time limitation was only measured by a single item. Thus, the internal consistency could not be shown in the present study. Even though this measure negatively correlated with the participants' perceived life expectancy (which was measured in the Adult Development and Aging Project), future research is recommended to employ the focus on limitations subscale (3-item) of the Future Time Perspective Scale [52] to obtain a comprehensive measure of this construct. Second, the current study was conducted involving a sample of Hong Kong Chinese adults, whose emotional and coping responses may not be generalized to other countries because the total infected cases in Hong Kong remained low (1035 confirmed cases as of 24 April 2020). Compared with other countries with over 100,000 infected cases and stringent lock-down measures, such as the United States, Italy and Spain, the threat perceived by the Hong Kong people may be relatively lower, thereby possibly facilitating more "adaptive" responses and behaviors. Third, this study only involved one assessment of emotional and coping responses to the pandemic. In view of the rapidly changing development of the COVID-19, future studies should consider adopting a daily diary design to understand the individual changes in emotional feelings and coping strategies over time. Fourth, approximately $3 \%$ of the participants in the current sample reported that their family members and friends were infected with COVID-19. It remains an open question how people's time perceptions and emotional and coping responses would be affected if their emotionally close social partners have been infected. Future studies should explore whether the mediating effects of perceived time limitation found in the present study will also be observed among COVID-19 patients or those with infected family members. Lastly, the present study did not control for the participants' levels of depression, which could be a confounding variable. Past studies have indicated that positive perceptions of aging are associated with lower levels of depression [53] and depression is differentially associated with the use of problem- and emotion-focused strategies [54]. Future studies should consider including depression when examining the relationships between subjective successful aging and coping responses.

\section{Conclusions}

To conclude, this study disclosed that perceiving oneself as successfully aging facilitates adaptive coping and affective wellbeing among middle-aged and older adults even in the face of the COVID-19 pandemic. This research also revealed the mediating role of perceived time limitation in the association between subjective successful aging and emotional responses and emotionfocused coping. The findings of this study indicated that building positive views of old age and perceived capacities to achieve successful aging, particularly through fostering their optimistic views of the future, are beneficial to buffer older adults from suffering from stressful events, such as the COVID-19 pandemic.

\section{List Of Abbreviations}

COVID-19: Coronavirus Disease 2019

HK: Hong Kong

HKSAR: Hong Kong Special Administrative Region

SARS: Severe Acute Respiratory Syndrome

\section{Declarations}

\section{Ethics approval and consent to participate}

Page 8/13 
The study was approved by the Human Subjects Ethics Sub-committee of the affiliated university (Reference no.: 3-4-201809_01 and B-PhD-202003-02). Written and oral informed consent form was obtained from all participants.

\section{Consent for publication}

Not applicable.

\section{Availability of data and materials}

The datasets used and/or analysed during the study are not publicly available due to the depository of the longitudinal database on Adult Development and Aging is still in progress but the data of the COVID-19 study are available from the corresponding author on reasonable request.

\section{Competing interests}

The authors declare that they have no competing interests.

\section{Funding}

The study was supported by an internal grant from City University of Hong Kong, which was awarded to Dannii Yeung (Project No: 9610403). The funders had no role in study design, data collection, data analyses, data interpretation, or preparation of the manuscript.

\section{Authors' contributions}

DY obtained the funding and designed the study. EC was involved in the quantitative data analyses. AL and AH were involved in data acquisition. All authors were involved in data interpretation and writing the paper. All authors read and approved the final manuscript.

\section{Acknowledgements}

The authors would like to thank Sherry Chong and Chichi Lam for their help in data collection.

\section{References}

1. Hong Kong SAR Government. 2020. Prevention and control of disease (requirement and directions) (business and premises) regulation gazetted. https://www.info.gov.hk/gia/general/202003/27/P2020032700878.htm. Accessed 31 May 2020.

2. Kwok KO, Li KK, Chan HH, Yi YY, Tang A, Wei WI, et al. Community responses during early phase of COVID-19 epidemic, Hong Kong. Emerg Infect Dis. 2020;26. https://doi.org/10.3201/eid2607.200500.

3. Hong Kong SAR Government. 2020. Latest situation of cases of COVID-19 (as of 17 May 2020). https://www.chp.gov.hk/files/pdf/local_situation_covid19_en.pdf. Accessed 31 May 2020.

4. Bowling A. Aspirations for older age in the 21st century: What is successful aging? Int J Aging Hum Dev. 2007;64(3): 263-97. https://doi.org/10.2190/LOK1-87W4-9R01-7127.

5. Cosco TD, Prina AM, Perales J, Stephan BCM, Brayne, C. Operational definitions of successful aging: A systematic review. Int Psychogeriatr. 2014;26(3):373-81. https://doi.org/10.1017/S1041610213002287.

6. Rowe JW, Kahn RL. Successful aging. New York: Dell Publishing; 1998.

7. Rowe JW, Kahn RL. Successful aging. Gerontologist. 1997;37(4):433-40. https://doi.org/10.1093/geront/37.4.433

8. Feng Q, Straughan PT. What does successful aging mean? Lay perception of successful aging among elderly Singaporeans. J GERONTOL B-PSYCHOL. 2017;72(2):204-13. https://doi.org/10.1093/geronb/gbw151.

9. Nakagawa T, Cho J, Yeung DY. Successful aging in East Asia: Comparison among China, Korea, and Japan. J GERONTOL BPSYCHOL. 2020. https://doi.org/10.1093/geronb/gbaa042.

10. Katz S, Calasanti T. Critical perspectives on successful aging: Does it "appeal more than it illuminates"? Gerontologist. 2015;55(1):26-33. https://doi.org/10.1093/geront/gnu027. 
11. Martinson M, Berridge C. Successful aging and its discontents: A systematic review of social gerontology literature. Gerontologist. 2015;55(1):58-69. https://doi.org/10.1093/geront/gnu037.

12. Ingrand I, Paccalin M, Liuu E, Gil R, Ingrand P. Positive perception of aging is a key predictor of quality-of-life in aging people. PLoS ONE. 2018;13(10):e0204044. https://doi.org/10.1371/journal.pone.0204044.

13. Pruchno RA, Wilson-Genderson M, Cartwright F. A two-factor model of successful aging. J GERONTOL B-PSYCHOL. 2010;65B(6):671-79. https://doi.org/10.1093/geronb/gbq051.

14. Reichstadt J, Sengupta G, Depp CA, Palinkas LA, Jeste DV. Older adults' perspectives on successful aging: Qualitative interviews. AM J GERIAT PSYCHIAT. 2010,18(7):567-75. https://doi.org/10.1097/JGP.0b013e3181e040bb.

15. Hsu HC, Jones BL. Multiple trajectories of successful aging of older and younger cohorts. Gerontologist. 2012;52(6):843-56. https://doi.org/10.1093/geront/gns005.

16. Østbye T, Krause KM, Norton MC, Tschanz J, Sanders L, Hayden K, et al. Ten dimensions of health and their relationships with overall self-reported health and survival in a predominately religiously active elderly population: The cache county memory study. J Am Geriatr Soc. 2006;54(2):199-209. https://doi.org/10.1111/j.1532-5415.2005.00583.x.

17. Montross LP, Depp C, Daly J, Reichstadt J, Golshan S, Moore D, et al. Correlates of self-rated successful aging among community-dwelling older adults. AM J GERIAT PSYCHIAT. 2006;14(1):43-51. https://doi.org/10.1097/01.JGP.0000192489.43179.31.

18. Feng Q, Son J, Zeng Y. Prevalence and correlates of successful ageing: A comparison between China and South Korea. Eur J Ageing. 2015;12:83-94. https://doi.org/10.1007/s10433-014-0329-5.

19. Stewart JM, Auais M, Belanger E, Phillips SP. Comparison of self-rated and objective successful ageing in an international cohort. Ageing Soc. 2019;39(7):1317-34. https://doi.org/10.1017/S0144686X17001489.

20. Strawbridge WJ, Wallhagen MI, Cohen RD. Successful aging and well-being: Self-rated compared with Rowe and Kahn. Gerontologist. 2002;42(6):727-33. https://doi.org/10.1093/geront/42.6.727.

21. Cernin PA, Lysack C, Lichtenberg PA. A comparison of self-rated and objectively measured successful aging constructs in an urban sample of African American older adults. Clin Gerontol. 2011;34(2):89-102.

https://doi.org/10.1080/07317115.2011.539525.

22. Levy BR, Slade MD, Kunkel SR, Kasl SV. Longevity increased by positive self-perceptions of aging. J Pers Soc Psychol. 2002;83(2):261-70. https://doi.org/10.1037/0022-3514.83.2.261.

23. Dutt AJ, Gabrian M, Wahl H-W. Developmental regulation and awareness of age-related change: A (mostly) unexplored connection. J GERONTOL B-PSYCHOL. 2018;73(6):934-43. https://doi.org/10.1093/geronb/gbw084.

24. Brassen S, Gamer M, Peters J, Gluth S, Büchel C. Don't look back in anger! Responsiveness to missed chances in successful and nonsuccessful aging. Science. 2012;336(6081):612-14. https://doi.org/10.1126/science.1217516.

25. Wrosch C, Scheier M, Miller E, Schulz R, Carver S. Adaptive self-regulation of unattainable goals: Goal disengagement, goal reengagement, and subjective well-being. Pers Soc Psychol Bull. 2003;29(12):1494-508.

https://doi.org/10.1177/0146167203256921.

26. Kahana E, Kahana B. Contextualizing successful aging: New directions in an age-old search. In: Settersten RJ, editor. Invitation to the life course: Toward new understanding of later life. New York: Baywood Publishing Company, Inc; 2003.

27. Ouwehand C, de Riddle DTD, Bensing JM. A review of successful aging models: Proposing proactive coping as an important additional strategy. Clin Psychol Rev. 2007;27(8):873-84. https://doi.org/10.1016/j.cpr.2006.11.003.

28. Fung HH, Carstensen LL. Goals change when life's fragility is primed: Lessons learned from older adults, the September 11 Attacks and SARS. Soc Cogn.2006;24(3):248-78. https://doi.org/10.1521/soco.2006.24.3.248.

29. Gabrian M, Dutt AJ, Wahl H-W. Subjective time perceptions and aging well: A review of concepts and empirical research-A mini-review. Gerontology. 2017;63(4):350-58. https://doi.org/10.1159/000470906.

30. Carstensen LL. The influence of a sense of time on human development. Science. 2006;312(5782):1913-5. https://doi.org/10.1126/science.1127488.

31. Fung HH, Carstensen LL. Motivational changes in response to blocked goals and foreshortened time: Testing alternatives to socioemotional selectivity theory. Psychol Aging. 2004;19(1):68-78. https://doi.org/10.1037/0882-7974.19.1.68.

Page $10 / 13$ 
32. Fung HH, Carstensen LL, Lutz AM. (1999). Influence of time on social preferences: Implications for life-span development. Psychol Aging. 1999;14(4):595-604. https://doi.org/10.1037/0882-7974.14.4.595.

33. Yeung DY, Fung HH, Kam C. Age differences in problem solving strategies: The mediating role of future time perspective. Pers Individ Differ. 2012;53(1):38-43. https://doi.org/10.1016/j.paid.2012.02.014.

34. Hoppmann CA, Infurna FJ, Ram N, Gerstorf D. Associations among individuals' perceptions of future time, individual resources, and subjective well-being in old age. J GERONTOL B-PSYCHOL. 2017;72(3):388-99.

https://doi.org/10.1093/geronb/gbv063.

35. Yeung DY, Ho AK-K. Focus on opportunities or limitations? Their effects on older workers' conflict management strategies. Manuscript under review

36. Yeung DY, Fung HH. Age differences in coping and emotional responses toward SARS: A longitudinal study of Hong Kong Chinese. Aging Ment Health. 2007;11(5):579-87. https://doi.org/10.1080/13607860601086355.

37. Hong Kong SAR Government. 2020. Prevention and control of disease (prohibition on group gathering) regulation. https://www.info.gov.hk/gia/general/202003/28/P2020032800720.htm?fontSize=1. Accessed 31 May 2020.

38. Fung HH, Yeung DY, Li K-K, Lang FR. Benefits of negative social exchanges for emotional closeness. J GERONTOL BPSYCHOL. 2009;64B(5):612-21. https://doi.org/10.1093/geronb/gbp065.

39. Hong Kong SAR Government. 2020. Entry restriction on non-Hong Kong residents coming from overseas extended [Press release]. https://www.info.gov.hk/gia/general/202004/06/P2020040600671.htm Accessed 31 May 2020.

40. Yeung DY, Fung HH, Chan DK-S. Roles of age and future time perspective of the work relationship in conflict management: A daily diary study. Int J Stress Manag. 2020. https://doi.org/10.1037/str0000155.

41. Carver CS. You want to measure coping but your protocol's too long: Consider the Brief COPE. Int J Behav Med. 1997;4(1):92100. https://doi.org/10.1207/s15327558ijbm0401_6.

42. Carstensen LL, Lang FR. Future time perspective scale [unpublished manuscript]. 1995. Located at: Stanford University, Stanford, CA.

43. Yeung DY, Fung HH, Lang FR. Gender differences in social network characteristics and psychological well-being among Hong Kong Chinese: The role of future time perspective and adherence to Renqing. Aging Ment Health. 2007;11(1):45-56. https://doi.org/10.1080/13607860600735820.

44. Rosseel Y. Lavaan: An R package for structural equation modeling. J Stat Softw. 2012;48(2):1-36. https://doi.org/10.18637/jss.v048.i02.

45. World Health Organization. 2020. COVID-19: Vulnerable and high risk groups. https://www.who.int/westernpacific/emergencies/covid-19/information/high-risk-groups. Accessed 31 May 2020.

46. Levy BR, Myers LM. Preventive health behaviors influenced by self-perceptions of aging. Prev Med. 2004;39(3):625-29. https://doi.org/10.1016/j.ypmed.2004.02.029.

47. Ho HCY, Yeung DY. Effects of occupational future time perspective on managing stressful work situations. Int J Psychol. 2016;51(4):261-8.

48. Tovel H, Carmel S. Maintaining successful aging: The role of coping patterns and resources. J Happiness Stud. 2014;15(2):255-70. https://doi.org/10.1007/s10902-013-9420-4.

49. Mellor D, Hayashi Y, Firth L, Stokes M, Chambers S, Cummins R. Volunteering and well-being: Do self-esteem, optimism, and perceived control mediate the relationship? J Soc Serv Res. 2008;34(4):61-70. https://doi.org/10.1080/01488370802162483.

50. Caldwell RL. At the confluence of memory and meaning-Life review with older adults and families: Using narrative therapy and the expressive arts to re-member and re-author stories of resilience. Fam J. 2005;13(2):172-5. https://doi.org/10.1177/1066480704273338.

51. Cohen A. Welfare clients' volunteering as a means of empowerment. Nonprofit Volunt Sect Q. 2009;38(3):522-34. https://doi.org/10.1177/0899764008320196.

52. Cate RA, John OP. Testing models of the structure and development of future time perspective: Maintaining a focus on opportunities in middle age. Psychol Aging. 2007;22(1):186-201. https://doi.org/10.1037/0882-7974.22.1.186. 
53. Bryant C, Bei B, Gilson K, Komiti A, Jackson H, Judd F. The relationship between attitudes to aging and physical and mental health in older adults. Int Psychogeriatr. 2012;24(10):1674-83. https://doi.org/10.1017/S1041610212000774.

54. Orzechowska A, Zajączkowska M, Talarowska M, Gałecki P. Depression and ways of coping with stress: A preliminary study. Med Sci Monit. 2013;19:1050-6. https://doi.org/10.12659/MSM.889778.

55. Chung EKH, Lam A, Yeung DY. Health-promoting behaviours and psychological well-being: The mediating role of sense of control. Manuscript under review.

\section{Tables}

Table 1 Descriptive statistics and correlations of major variables $(\mathrm{N}=311)$

\begin{tabular}{|c|c|c|c|c|c|c|c|c|c|c|c|c|c|c|}
\hline & & $\begin{array}{l}\text { Mean } \\
(S D) / \% \\
\end{array}$ & 1. & 2. & 3. & 4. & 5. & 6. & 7. & 8. & 9 . & 10 . & 11. & 12. \\
\hline 1. & Age & $\begin{array}{c}64.58 \\
(10.14)\end{array}$ & & & & & & & & & & & & \\
\hline 2. & $\begin{array}{l}\text { Gender } \\
\text { (Female) }\end{array}$ & $73 \%$ & .05 & & & & & & & & & & & \\
\hline 3. & Education & $\begin{array}{l}1.94 \\
(.62)\end{array}$ & $-.40^{* *}$ & $-.34^{* *}$ & & & & & & & & & & \\
\hline 4. & $\begin{array}{l}\text { Work } \\
\text { status } \\
\text { (Employed) }\end{array}$ & $25.40 \%$ & $-.52^{* *}$ & -.04 & $.24^{* *}$ & & & & & & & & & \\
\hline 5. & $\begin{array}{l}\text { Perceived } \\
\text { severity }\end{array}$ & $\begin{array}{l}3.69 \\
(.95)\end{array}$ & .03 & .08 & $-.16^{* *}$ & -.04 & & & & & & & & \\
\hline 6. & $\begin{array}{l}\text { Level of } \\
\text { reduced } \\
\text { social } \\
\text { contact }\end{array}$ & $\begin{array}{c}4.04 \\
(1.02)\end{array}$ & -.10 & .07 & -.01 & .06 & $.22^{* * *}$ & & & & & & & \\
\hline 7. & $\begin{array}{l}\text { Perceived } \\
\text { time } \\
\text { limitation }\end{array}$ & $\begin{array}{c}3.32 \\
(1.13)\end{array}$ & -.02 & $.14^{*}$ & -.10 & -.01 & $.19^{* *}$ & .09 & & & & & & \\
\hline 8. & $\begin{array}{l}\text { Subjective } \\
\text { successful } \\
\text { aging }\end{array}$ & $\begin{array}{c}5.03 \\
(1.66)\end{array}$ & .14 & -.07 & .11 & $-.17^{* *}$ & -.09 & -.03 & $-.18^{* *}$ & & & & & \\
\hline 9. & $\begin{array}{l}\text { Negative } \\
\text { emotions }\end{array}$ & $\begin{array}{l}2.81 \\
(.03)\end{array}$ & .05 & $.20^{* *}$ & $-.27^{* *}$ & -.10 & $.32^{* * *}$ & $.19^{* *}$ & $.35^{* *}$ & $-.31^{* * *}$ & & & & \\
\hline 10 . & $\begin{array}{l}\text { Positive } \\
\text { emotions }\end{array}$ & $\begin{array}{l}2.81 \\
(.85)\end{array}$ & $.17^{* *}$ & .08 & .01 & $-.13^{*}$ & -.00 & -.03 & $-.20^{* *}$ & $.40^{* * *}$ & $-.28^{* *}$ & & & \\
\hline 11. & $\begin{array}{l}\text { Negative } \\
\text { reactions } \\
\text { to reduced } \\
\text { social } \\
\text { contact }\end{array}$ & $\begin{array}{c}2.94 \\
(1.14)\end{array}$ & .03 & $.12^{*}$ & $-.19^{* *}$ & -.07 & $.30^{* * *}$ & $.25^{* * *}$ & $.26^{* *}$ & $-.25^{* * *}$ & $.58^{* *}$ & $-.23^{* *}$ & & \\
\hline 12. & $\begin{array}{l}\text { Problem- } \\
\text { focused } \\
\text { coping }\end{array}$ & $\begin{array}{l}3.41 \\
(.72)\end{array}$ & .03 & $.12^{*}$ & .03 & .03 & $.18^{* *}$ & $.14^{*}$ & .01 & $24^{* * *}$ & .05 & $.25^{* *}$ & .07 & \\
\hline 13. & $\begin{array}{l}\text { Emotion- } \\
\text { focused } \\
\text { coping }\end{array}$ & $\begin{array}{l}2.67 \\
(.73)\end{array}$ & .09 & $.15^{* *}$ & -.07 & -.07 & $.21^{* * *}$ & .11 & $.23^{* *}$ & $.12^{*}$ & $.32^{* *}$ & $.18^{* *}$ & $.25^{* *}$ & $.36^{* *}$ \\
\hline
\end{tabular}

Note. Gender was coded as $1=$ male and 2 = female. Education was coded as $1=$ primary school education or below, $2=$ secondary school education, and $3=$ Bachelor's degree or above. Work status was coded as $0=$ not employed and $1=$ employed during the pandemic.

$* p<.05 ; * * p<.01 ; * * * p<.001$.

Table 2 Total, Direct and Indirect Effects of Subjective Successful Aging on Emotional and Coping Responses through Perceived Time Limitation 


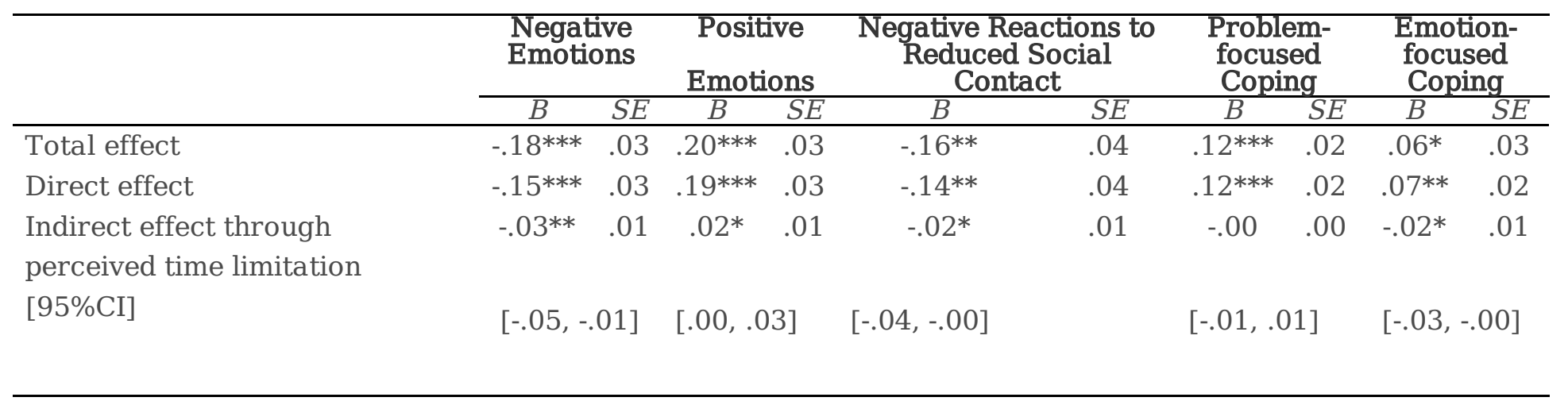

Note. In the mediation model, subjective successful aging and perceived time limitation were inputted as the independent variable and mediator, respectively. Age, gender, education level, work status, perceived severity, and level of reduced social contact were statistically controlled as covariates in mediation analysis.

${ }^{*} p<.05 ; * * p<.01 ; * * * p<.001$.

\section{Figures}

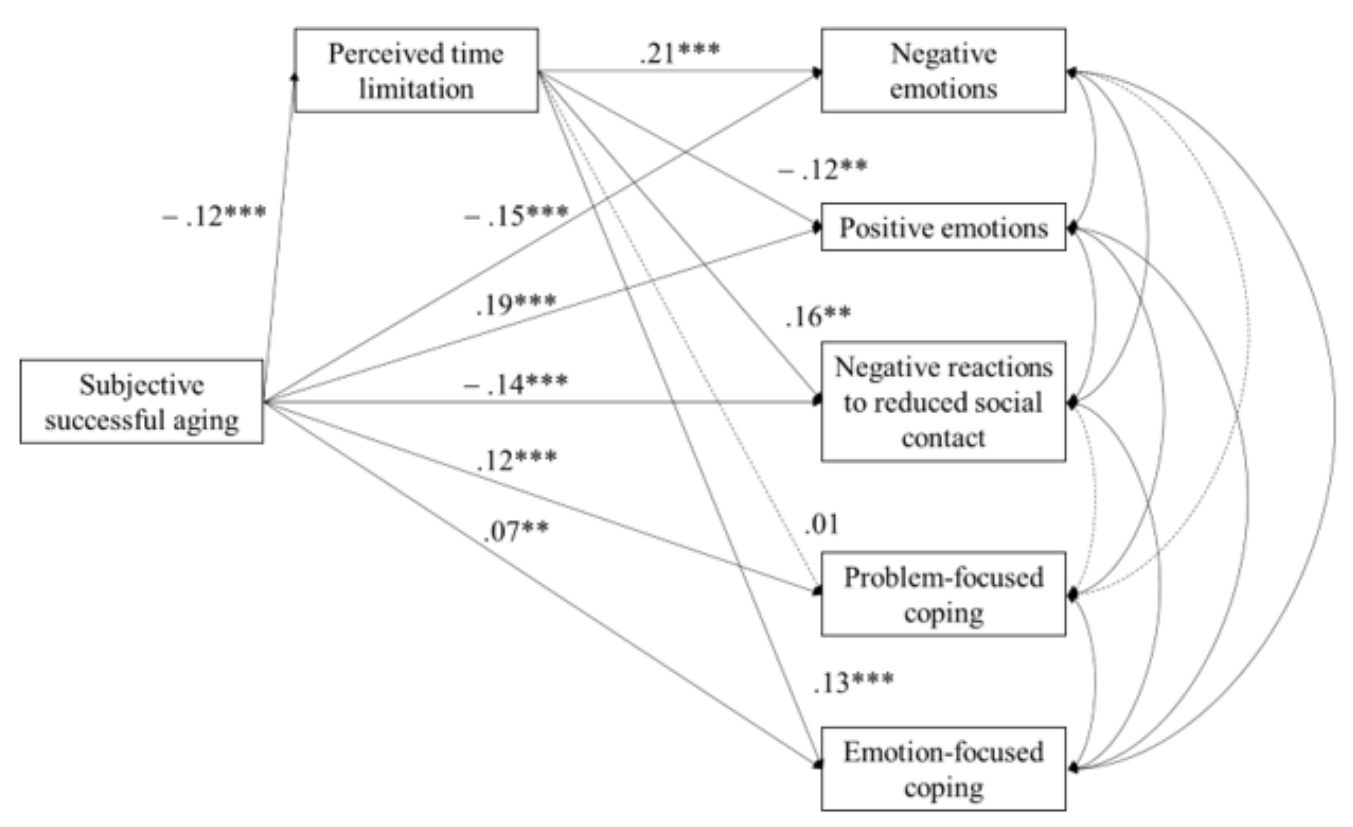

Figure 1

The mediation model on the relationships between subjective successful aging and five outcome variables through perceived time limitation. Note. Numbers in the figure indicate unstandardized regression coefficients. Age, gender, education level, work status, perceived severity, and level of reduced social contact were statistically controlled as covariates in the mediation analysis. Goodness of fit of this mediation model: $\chi 2=14.30(\mathrm{df}=6, \mathrm{p}=.026), \mathrm{CFI}=.98, \mathrm{RMSEA}=.07, \mathrm{SRMR}=.03 .{ }^{*} \mathrm{p}<.05 ;{ }^{* \star} \mathrm{p}<.01$; ${ }^{\star \star \star} \mathrm{p}$ $<.001$.

\section{Supplementary Files}

This is a list of supplementary files associated with this preprint. Click to download.

- SupplementaryCOVID19HK.docx 